\title{
Modifiye Nanobentonitle Sulu Ortamdan Fenol ve 4-Klorofenolün Giderilmesi
}

\author{
Mustafa Uçar ${ }^{*}$, Dilek Kayıran ${ }^{2}$, Atilla Evcin ${ }^{3}$ \\ 1*Afyon Kocatepe Üniversitesi, Fen Edebiyat Fakültesi, Kimya Bölümü, Afyonkarahisar, Türkiye (ORCID: 0000-0003-1445-3361), ucarm@ aku.edu.tr \\ ${ }^{2}$ Afyon Kocatepe Üniversitesi, Fen Edebiyat Fakültesi, Kimya Bölümü, Afyonkarahisar, Türkiye (ORCID: 0000-0002-2282-1374), dilekkayiran@ hotmail.com \\ ${ }^{3}$ Afyon Kocatepe Üniversitesi, Mühendislik Fakültesi, Malzeme Bilimi ve Mühendisliği Bölümü, Afyonkarahisar, Türkiye (ORCID: 0000-0002-0163-5097), \\ evcin@aku.edu.tr
}

(İlk Geliş Tarihi 27 Temmuz 2020 ve Kabul Tarihi 10 Aralık 2020)

(DOI: $10.31590 /$ ejosat.774567)

ATIF/REFERENCE: Uçar, M., Kayıran, D., Evcin, A. (2020). Modifiye Nanobentonitle Sulu Ortamdan Fenol ve 4-Klorofenolün Giderilmesi. Avrupa Bilim ve Teknoloji Dergisi, (20), 760-768.

\section{$\ddot{O ̈ z}$}

Son yıllarda endüstri ve tarımda kullanılan kimyasal ve ilaçlar deşarj edildikleri ortamlarda tüm canlılar için zararlı olmaya başlamıştır. Çevre koruma ajansları ve belediye gibi kurumların bu konudaki hazırladıkları yönetmeliklerle zararlı kimyasallar sınıflandırılmış ve atık sularda bulunabilecek minimum derişimler belirlenmiştir. Bu sınır değerler dışında kalan atık sular için saflaştırma ve arıtma prosesleri zorunlu hale gelmiştir. Çalışmamızda fenol (P) ve 4-klorofenolün (4-CP) modifiye alkil amonyum nanobentonit (MANB) ile kesikli sistemde, sulu çözeltiden giderimi araştırılmıştır. P ve 4-CP adsorplanmasında denge zamanı, konsantrasyon, $\mathrm{pH}$ etkisi, adsorbent dozaj etkisi ve desorpsiyonu incelenmiştir. Adsorplanan miktarı; P için 4,69 mg/g, 4-CP için 6,18 mg/g olarak elde edilmiştir. Denge zamanı 45 dak. olup adsorbentin desorpsiyonu \% $30(v / v)^{\prime}$ luk etil alkol ortamında yapılmıştır. Adsorpsiyon deneyleri 25,35 ve $45^{\circ} \mathrm{C}$ değişik sıcaklık aralıklarında yapılmıştır. Örneklerin kimyasal yapı, termal ve morfolojik karakterizasyonu başlangıçta ve adsorpsiyondan sonra yapılmıştır. Çalışılan maddelerin başlangıç derişiminin MANB mikrokürelerin Langmuir ve Freundlich adsorpsiyon izoterm modellerine uygunluğu incelenmiştir.

\section{Removal of Phenol and 4-Chlorophenol from Aqueous Environment with Modified Nanobentonite}

\begin{abstract}
In recent years, chemicals and drugs used in industry and agriculture have started to be harmful to all living things in the environments in which they are discharged. With the regulations prepared by environmental protection agencies and municipalities, hazardous chemicals are classified and minimum concentrations in wastewater are determined. Purification and purification processes have become mandatory for wastewater outside these limit values. In our study, the removal of phenol (P) and 4-chlorophenol (4-CP) with modified alkyl ammonium nanobentonite (MANB) from the aqueous solution was investigated. Balance time, concentration, $\mathrm{pH}$ effect, adsorban dosage effect and desorption were investigated in P and 4-CP adsorption. Adsorbed amount; $4.69 \mathrm{mg} / \mathrm{g}$ for P and 6.18 $\mathrm{mg} / \mathrm{g}$ for $4-\mathrm{CP}$. Balance time $45 \mathrm{~min}$. and the adsorbent desorption was performed in $30 \%$ ( $v / v$ ) ethyl alcohol medium. Adsorption experiments were carried out at different temperature ranges of 25,35 and $45^{\circ} \mathrm{C}$. Chemical structure, thermal and morphological characterization of samples were performed at the beginning and after adsorption. The suitability of the initial concentrations of the studied substances to the MANB microspheres was investigated for Langmuir and Freundlich adsorption isotherm models.
\end{abstract}

Keywords: Nanobentonite, Modification, Adsorbent, Phenols, Wastewater.

\footnotetext{
*Corresponding Author: ucarm@aku.edu.tr
} 


\section{Giriş}

Bentonitler, ağırlıklı olarak smektit kil minerallerinden oluşan, sulu ortamda şişme özelliğine sahip, asidik ortamda aktiflleştirilebilen, geniş yüzey alanlı bir kildir. Ülkemizde Tokat, Edirne, Çankırı, Ordu, Giresun ve Konya'daki maden ocaklarından çıkarılmaktadır. Fiziksel ve kimyasal özellikleri bakımından endüstride geniş kullanım alanları mevcuttur (İpekoğlu vd., 1997).

Fenoller ve türevleri, atık sudaki önemli miktarları ile günümüz yaşamında yaygın olarak kullanılan kimyasallardır. Klorofenoller (CP'ler) organik kökenli kirletici sınıfına dahildir. Klorofenoller insan sinir ve solunum sistemlerini ciddi şekilde etkiler ve ciddi sağlık tehlikelerine neden olur. Güçlü bir kokuya sahip, biyolojik olarak parçalanabilirliği zayıf, toksik ve kanserojen özelliklere sahip ortamlarda kalıcıdırlar. Çevre Koruma Ajansı (EPA) P ve 4-CP'leri tehlikeli kirleticiler olarak sınıflandırmış olup, bunların giderilmesi ve tayinlerine büyük önem vermiştir (Uçar 2019, Uçar vd., 2020). Bu gibi kirleticilerin su ortamından uzaklaştırılmasında çeşitli yöntemler mevcuttur. Bunlar arasinda biyodegradasyon (Olaniran and Igbinosa 2011), ileri oksidasyon prosesleri ile oksidasyon (Pera vd., 2004) ve adsorpsiyon (Dabrowski vd., 2005, Soto vd., 2011) en yaygın kullanılanlardır (Kuśmierek 2016). Bu bileşiklerin su ortamından uzaklaştırılmasında bir çok farklı hammadde, kimyasal ve polimer kullanılmış olup, bunların başında zeolit, bentonit, sepiyolit, modifiye edilmiş manyetik maya ve polimerik mikroküreler gibi değişik adsorbentler gelmektedir (Şenel vd., 2006, Kuleyin 2007, Uçar vd., 2009, Denizli vd., 2001, Denizli vd., 2002, Evcin vd., 2014, Uçar vd., 2014, Uçar vd, 2015, Uçar 2019, Uçar vd., 2020).

Literatürde yapılan çalışmalara bakıldığında, Nourmoradi ve arkadaşları yaptıkları çalışmada, sulu çözeltilerden 4-CP uzaklaştırmak için iki katyonik yüzey aktif madde (heksa desil trimetil amonyum bromür, HDTMA ve tetra desil trimetil amonyum bromür, TTAB) ile modifiye edilmiş montmorillonit (Mt) kullanmışlardır (Nourmoradi vd., 2016).

Hernandez ve arkadaşları çalışmalarında kil aljinat nanokompozitlerinin özellikleri farklı $\mathrm{P}$ ve 4-CP'ün sulu çözeltilerden uzaklaştırılması değerlendirilmiştir. Bu amaçla, Mt. sentezlenen kompozitler için kullanılmıştır. İlki, Mt. Puebla Eyaletinden (Meksika eyaleti) ham mineral; ikincisi, organo modifiye edilmiş bir Mt. heksadesil trimetilamonyum iyonları (HDTMA) ile; ve üçüncüsü, dialkil dimetilamin iyonları (C14C18) ile modifiye edilmiş ticari bir kildir. Morfolojileri, termal ve spektroskopik özellikleri değerlendirilmiş, maksimum adsorpsiyon kapasiteleri hesaplanmış ve kinetik adsorpsiyon modelleri incelenmiştir (Hernandez vd., 2018).

Garmia ve arkadaşları, kompozit organo bentonit / aljinat taneciklerinin çıkarılması için adsorbanlar olarak potansiyelini araştırmıştır. Sulu çözeltiden 2,4-diklorofenolün (2,4 DCP) uzaklaştırılması için bentonit, ilk önce katyonik yüzey aktif maddeler oktadesil trimetil amonyum, heksadesil trimetil amonyum ve fenil trimetil amonyum ile modifiye edilmiş, daha sonra adsorban kompozit boncuklar oluşturmak için kalsiyum aljinat ile kapsüllenmiştir. Örneklerin yapısal özelliklerindeki değişimi incelemek için X ışını kırınımı kullanılmıştır (Garmia vd., 2018).

Banat ve arkadaşları tarafindan (2000), sulu çözeltilerden bentonitle P'nin adsorpsiyon potansiyeli araştırıldı. Temas e-ISSN: 2148-2683 süresi, başlangıç konsantrasyonu, pH, çözücünün varlığı ve bentonitin desorpsiyon karakteristiklerinin değerlendirilmesi için kinetik ve izoterm çalışmaları gerçekleştirilmiştir. P'ün adsorpsiyonunun, artan P konsantrasyonu ile arttığ 1 ve çözelti $\mathrm{pH}$ değerinin artmasıyla azaldığı görülmüştür.

Aksu ve Yener, klorofenolleri (o-klorofenol ve p-klorofenol) uzaklaştırmak için granül aktive edilmiş karbonun yerine kurutulmuş aktive edilmiş çamur ve uçucu külün kullanımı incelenmiştir. Sonuçlar, tüm mono-klorlanmış P-sorbent sistemleri için denge verilerinin Redlich-Peterson modelini incelenen konsantrasyon aralığında en iyi şekilde uyduğunu göstermiştir (Aksu ve Yener 2001).

PHEMA mikro boncuklarını taşıyan Cibacron Blue F3GA, klorofenollerin (P, m-klorofenol (3-CP), 4-CP ve 2,4,6triklorofenol (2,4,6-TCP)) giderilmesi için araştırıldı. PHEMA mikro küreler, bir başlatıcı (azobisisobutyronitril) varlığında HEMA'nın modifiye edilmiş süspansiyon polimerizasyonu ile hazırlandı. Klorofenollerin Cibacron Blue taşıyan mikro kürelere maksimum adsorpsiyon siras1: 3-CP > 4-CP > 2,4,6-TCP > P şeklindedir. CP'lerin adsorpsiyonu $\mathrm{pH}$ arttıkça azalmıştır (Denizli vd., 2001). P ve CP'ler üzerine yaptığımız benzer çalışmalarda bulunmaktadır (Denizli vd., 2002, Uçar vd., 2014, Evcin vd., 2014, Uçar vd. 2015, Uçar 2019).

$\mathrm{P}$ ve türevlerinin aktif karbonlar üzerine adsorpsiyonu, bu konuyla ilgili çok sayıda makaleye dayanmaktadır. Bu olayın üzerinde karbon türü, karbon yüzey işlevleri, bir arada var olan sıvı fazının $\mathrm{pH}$ değeri, oksijen varlığı, elektrolitlerin eklenmesi, vb. çok sayıda faktörün önemli etkisi olduğu bilinmektedir (Dabrowski vd., 2005).

Kuleyin tarafindan yapılan çalışmada, $P$ ve 4-CPün sürfaktan ile modifiye edilmiş zeolit tarafından adsorpsiyon özellikleri araştırılmıştır. Temas süresi, adsorban doz, başlangıç konsantrasyonu ve sicaklık gibi çeşitli deneysel parametrelerin $\mathrm{P}$ ve 4-CP'ün uzaklaştırılması üzerindeki etkilerini değerlendirmek için bir başka çalışma daha yapılmıştır (Kuleyin 2007).

Sanjay ve arkadaşları $P$ ve 2-CP'ün uzaklaştırılmasının karşılaştırılması ticari zeolit-Y, FAZ-Y ve SMZ-Y kullanılarak da çalışılmışlardır. $\mathrm{pH}$, adsorban dozu ve konsantrasyonun $\mathrm{P}$ ve 2-CP'ün adsorpsiyonu üzerindeki etkisi gibi çeşitli parametrelerin etkisi ayrıntılı olarak incelenmiştir. Anyon varlığının $\mathrm{P}$ ve 2-CP'ün adsorpsiyonu üzerindeki etkisi de araştırılmıştır. $P$ ve 2-CP'ün adsorpsiyonu üzerine yapılmış benzer çalışmada, yüzeyi uçucu kül ile modifiye edilmiş zeolitler kullanılarak atık sulardan $\mathrm{P}$ ve 2- CP'leri uzaklaştırmak için metod geliştirilmiştir (Sanjay vd., 2008).

Ahmaruzzaman, derleme çalışmasında doğal adsorban malzemelerin eleştirel bir analizini ve özelliklerini, avantajlarını ve sınırlamalarını açıklamıştır. Bu derleme makalesinde tartışılan fenolik bileşiklerin adsorpsiyonu ile ilgili çeşitli sorunlar ve dezavantajlar vardır. İncelemeden, düşük maliyetli adsorbanların belirli fenolik bileşikler için yüksek ayırma kabiliyetleri gösterdiği açıktır (Ahmaruzzaman 2008).

Majdan ve arkadaşları, sodyum bentonit ile modifiye edilmiş dimetilbenziloktadesilamonyum klorür (DMBOAK), spektral ve $X$ 1şınları analizlerini incelemişlerdir. FT-IR spektrumlarında asimetrik ve simetrik gerilme titreşimleri, yüzey aktif madde derişimiyle bentonit fazda metilen zinciri daha düşük frekanslara doğru $\mathrm{CH}_{2}$ simetrik gerilme titreşimleri ortaya çıktığını göstermiştir (Majdan vd., 2008). 
Şentürk vd. (2009) tarafından yapılan çalışmada katyonik bir yüzey aktif maddesi, setil trimetilamonyum bromür (CTAB) ile modifiye edilmiş doğal bir bentonit, P'nin sulu çözeltilerden uzaklaştırılması için bir adsorban olarak kullanıldı. Doğal ve modifiye edilmiş bentonitler (organobentonit) bazı enstrümental tekniklerle (FTIR, XRD ve SEM) karakterize edildi. Adsorpsiyon çalışmaları bir kesikli sistemde gerçekleştirildi ve çözelti pH'1, temas süresi, başlangıç $\mathrm{P}$ konsantrasyonu, organobentonit konsantrasyonu ve sıcaklık gibi çeşitli deneysel parametrelerin etkileri organobentonite $\mathrm{P}$ adsorpsiyonu üzerine değerlendirildi. Maksimum $\mathrm{P}$ giderimi pH 9,0'da gözlendi.

Uçar vd çalışmasında, çok çeşitli toksik bileşiklerden, özellikle aromatik moleküllerden gelen suyun kimyasal kontaminasyonu, insan toksisiteleri nedeniyle ciddi bir çevresel sorundur. $\mathrm{Bu}$ çalışmada, $\mathrm{P}$ ve $\mathrm{CP}$ 'lerin uzaklaştırılması için Manisa-Gördes bölgesinden (AMGC) aktifleştirilmiş klinoptilolit araştırılmıştır (Uçar vd., 2015).

\section{Materyal ve Metot}

\subsection{Materyal}

Deneysel çalışmdaki başlangıç maddeleri (P, 4-CP, etil alkol $\left.\left(\mathrm{C}_{2} \mathrm{H}_{5} \mathrm{OH}\right), \mathrm{HCl}, \mathrm{CH}_{3} \mathrm{COOH} / \mathrm{NaCH}_{3} \mathrm{COO}, \mathrm{NaOH}, \mathrm{NH}_{3} / \mathrm{NH}_{4}\right)$ Merck kalitesinde olup herhangi bir saflaştırma işlemine tabi tutulmadan kullanılmıştır.

\subsubsection{Bentonit}

Bu çalışmada MANB kullanılmıştır. Nanobentonitin modifikasyonu ilgili literatürde ayrıntılı olarak verilmiştir (Majdan vd., 2008). Çalışmada kullanılan bentonitin XRF analizi Tablo 1 de verilmiştir.

Tablo 1. Çalışmada kullanılan bentonitin XRF analizi $(\% W)$

\begin{tabular}{c|c|c|c|c|c|c|c|c}
\hline $\mathbf{S i O}_{2}$ & $\mathbf{A l}_{2} \mathbf{O}_{3}$ & $\mathbf{F e}_{2} \mathbf{O}_{3}$ & $\mathbf{C a O}$ & $\mathbf{M g O}$ & $\mathbf{K}_{2} \mathbf{O}$ & $\mathbf{N a}_{2} \mathbf{O}$ & $\mathbf{P}_{2} \mathbf{O}_{5}$ & $\mathbf{S O}_{3}$ \\
\hline 47,42 & 16,60 & 2,54 & 1,92 & 2,77 & 0,27 & 0,13 & 0,10 & 0,01 \\
\hline $\mathbf{F}$ & $\mathbf{C l}$ & $\mathbf{T i O}_{2}$ & $\mathbf{M n O}$ & $\mathbf{Z n O}$ & $\mathbf{A s}_{2} \mathbf{O}_{3}$ & $\mathbf{Z r O}_{2}$ & $\mathbf{N b}_{2} \mathbf{O}_{5}$ & $\begin{array}{c}\mathbf{A . Z .} \\
(\mathbf{L O I})\end{array}$ \\
\hline 0,12 & 0,08 & 0,13 & 0,07 & 0,01 & 0,01 & 0,01 & 0,07 & 27,79 \\
\hline
\end{tabular}

A.Z. (LOI) : Ateş zayiatı

\subsection{Adsorpsiyon Deneyleri}

Adsorpsiyon deneyleri için stok çözeltiler hzırlanmış ve değişik konsantrasyonlarda çalışılmıştır. Farklı başlangıç denge çalışmalarında 4-CP (10-400 ppm) konsantrasyonları kullanılmıştır. Adsorpsiyon kinetiği, denge ve termodinamiğin ölçülmesine yönelik deneysel prosedürler, önceki çalışmalarımızda ayrıntılı olarak tarif edilmiş ve tartışılmıştır (Denizli vd., 2001, Denizli vd., 2002, Uçar vd., 2014, Evcin vd., 2014, Uçar vd., 2015, Uçar 2019). 4-CP'nin konsantrasyonu, 280 nm'de DR 5000 spektrofotometre kullanılarak belirlendi. Adsorpsiyon kapasitesi Denklem (1) kullanılarak hesaplandı:

$q_{e}=\frac{\left(C_{0}-C_{e}\right) * V}{m}$

Denklemde;

$\mathrm{q}_{\mathrm{e}}=$ Dengedeki adsorplanan madde miktarı, $\mathrm{mg} / \mathrm{g}$

$\mathrm{C}_{\mathrm{o}}=$ Başlangıçtaki P ve 4-CP derişimi, mg/L

$\mathrm{C}_{\mathrm{e}}=$ Dengeki çözeltide $\mathrm{P}$ ve 4-CP derişimi, mg/L

$\mathrm{V}=$ Çözelti hacmi, L

$\mathrm{m}=$ Adsorban miktarı, $\mathrm{g}$
Kalibrasyon ve adsorpsiyon deneyleri işlem basamakları Şekil 1 ve Şekil 2 ' de verilmiştir. Konsantrasyon aralığı 100 1000 ppm, sicaklık aralığ 1 ise $25^{\circ} \mathrm{C}, 35^{\circ} \mathrm{C}$ ve $45^{\circ} \mathrm{C}$ olarak seçilmiştir.

\section{Stok çözeltilerin hazurlanması (100 ppm)}

Numune çözeltilerinin hazırlanması $(10 \mathrm{~mL})$

pH ayan (Tampon Çözelti)

$\mathrm{pH}$ metre ile $\mathrm{pH}$ ayarlama

Mekanik karıştincıda kanş̧tırma (200

devir/dakika)

\section{Absorbans okunmasi}

Şekil 1 Kalibrasyon deneyleri işlem adımları. 


\subsection{Katyon Değişim Kapasitesi}

Bir kilin katyon değişim kapasitesi (KDK), toprak yüzeylerinde kalsiyum $\left(\mathrm{Ca}^{2+}\right)$, magnezyum $\left(\mathrm{Mg}^{2+}\right)$ ve potasyum $\left(\mathrm{K}^{+}\right)$gibi pozitif yüklü iyonları (katyonlar) tutabilen negatif yüklü alanların miktarının bir ölçüsüdür. Elektrostatik kuvvetlerle tutulan katyonlar elektrostatik olarak kil çözeltisindeki katyonlarla kolayca değiştirilebilir, böylece daha yüksek bir KDK değerine sahip bir kil, düşük KDK değerine sahip bir kile göre yeterli miktarlarda $\mathrm{Ca}^{2+}, \mathrm{Mg}^{2+}$ ve $\mathrm{K}^{+}$ muhafaza etme kapasitesine sahiptir. Bentonitin KDK değeri ASTM 837C standartları izlenerek hesaplanmıştır.

\subsection{Rejenarasyon Deneyleri}

Toksik kirleticilerin uzaklaştırılması için adsorpsiyon teknolojisi, kirletici desorpsiyonundan sonra adsorbanların rejenerasyonunun verimliliğine bağlıdır. Biriktirilen kirleticiler hafif ve ucuz desorbing maddesi kullanılarak yıkanır (desorbe edilir) ve daha sonra adsorbent başka bir döngü için yeniden üretilir. Adsorbanın rejenerasyonu, işlem maliyetini düşük tutmak için çok önemli olabilir. Bu çalışmada da adsorpsiyondan sonra, adsorbent \% $30(v / v)$ 'luk etanol çözeltisiyle rejenere edilmiştir.

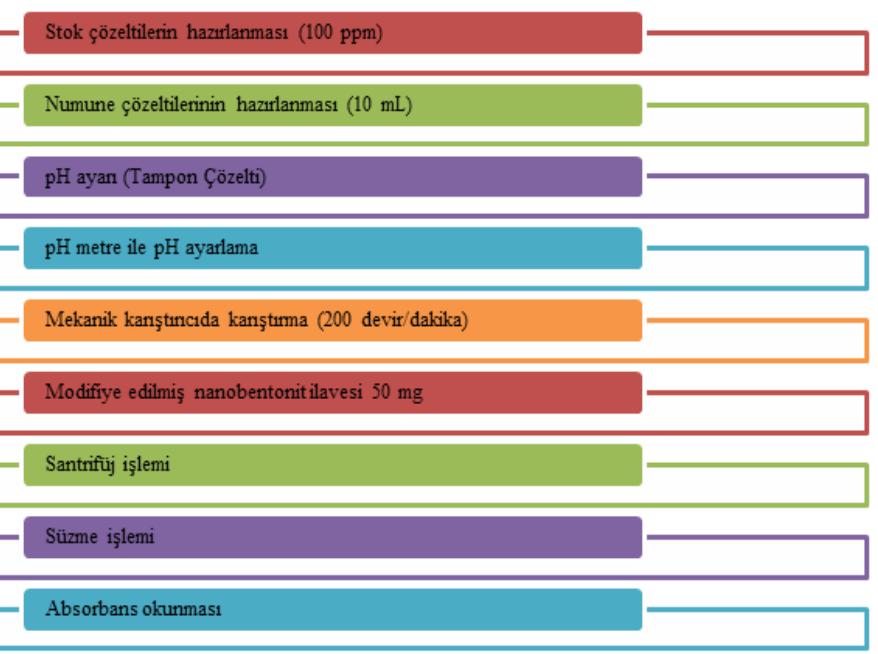

Şekil 2 Absorpsiyon deney adımları

\section{Araştırma Sonuçları ve Tartışma}

\subsection{XRD Analiz Sonuçları}

X 1şını difraksiyonu (XRD), kristalin malzemelerin karakterizasyonu için güçlü bir tahribatsız tekniktir. Yapılar, fazlar, tercih edilen kristal yönelimleri (doku) ve ortalama tane büyüklüğü, kristallik, gerilim ve kristal kusurları gibi diğer yapısal parametreler hakkında bilgi sağlar (Dann, 2002). Şekil 3 'de Nanobentonit örneğinin XRD analizi verilmiştir.

Modifikasyon işleminin etkisini görebilmek amacıyla nanobentonit örneklerinden adsorpsiyondan önce ve sonra numuneler analiz edilmiştir. Analizlerindeki ana fazlar smektit, illit-mika, kaolinit, kuvars, kalsit olarak elde edilmiştir. Modifiye edilmiş nanobentonitin katman kalınlığı 17,83 iken MANB, P ve 4-CP adsorpladığında değeri 18,01 'e yükselmiştir. Modifikasyondan sonra adsorbentin $P$ ve 4-CP'ü adsorpladığında katman kalınlığında değişim gözlenmiştir.

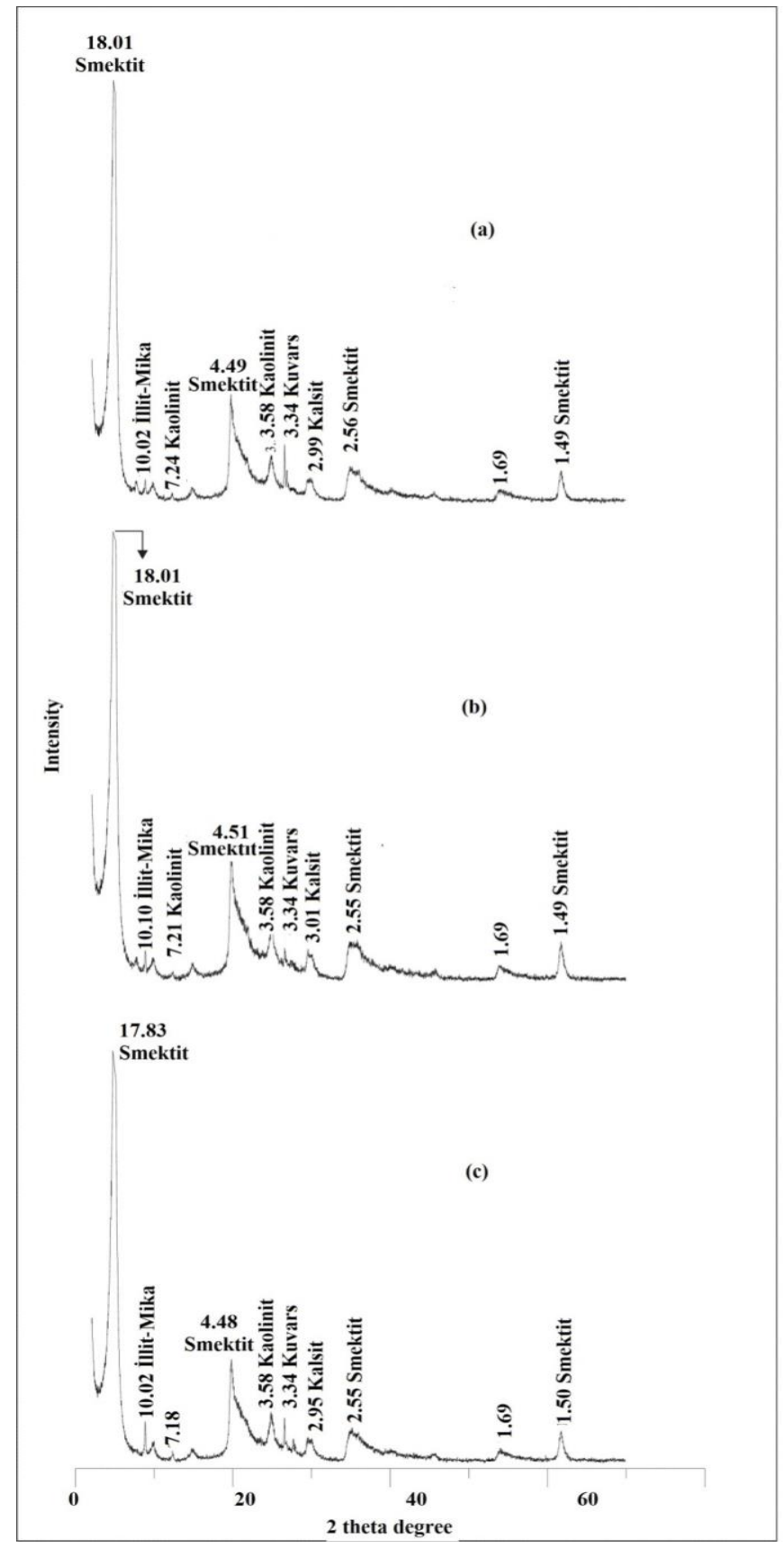

Şekil 3 MANB'in b) 4-CP adsorpsiyon sonrast ve c) adsorpsiyon öncesi XRD analizi.

\subsection{SEM ve EDX Analizleri}

Taramalı elektron mikroskobu, yüksek çözünürlüklü görüntüleme, element analizi ve son zamanlarda kristalografik analizin değerli bir kombinasyonunu sunar. Bentonit gibi iletken olmayan numuneler altın, bakır, platin, altın ve karbon gibi malzemelerle magnetron sıçratma tekniğiyle kaplanarak analize hazır hale getirilir. Karbon kaplı P ve 4-CP'ün adsorpsiyon öncesi ve sonrasındaki SEM fotoğrafları Şekil $4 a$, 4b ve $4 c^{\prime}$ de gösterilmiştir. 

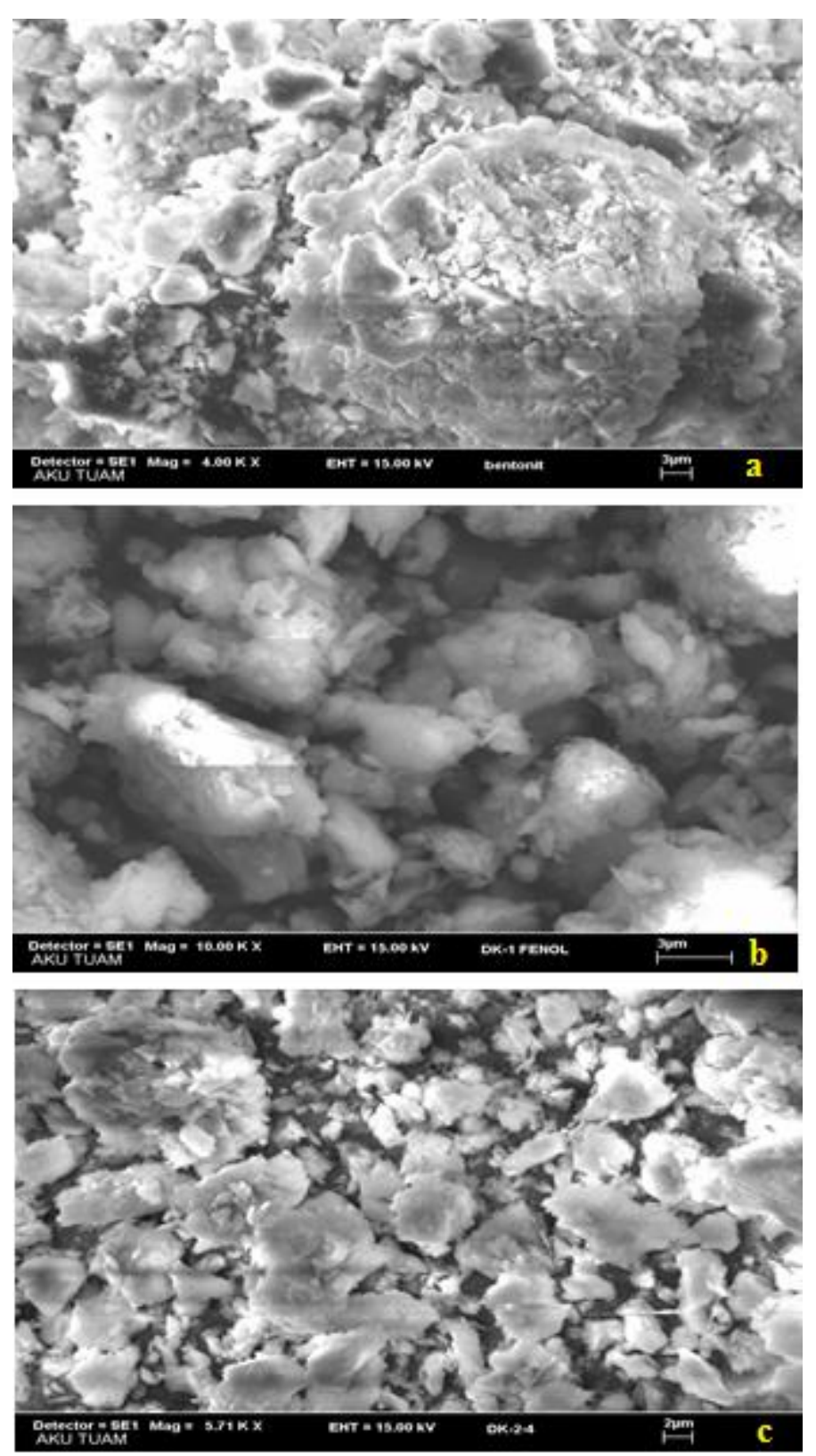

Şekil 4. MANB'in SEM analiz görüntüsü a) adsorpsiyon öncesi b) P adsorpsiyon sonrası c) 4-CP adsorpsiyon sonrast.

Energy Dispersive X-ray (EDX) mikroanalizi, numunelerde bulunan elementlerin varlığını ortaya koyan karakteristik $\mathrm{X}$ ışınlarının üretimine dayanan elektron mikroskopisine bağlı temel analiz tekniğidir. $\mathrm{P}$ ve 4-CP'ün adsorpsiyon öncesi ve sonrasındaki EDX verileri Şekil 5a, 5b ve 5c'de verilmiştir. Şekil 5 'den MANB'in adsorpsiyon öncesinde oksijen, magnezyum, alüminyum, silisyum, kalsiyum ve demir gibi elementler belirlenmiş olup, bu elementler simektitin mineral yapısını oluşturmaktadır. Elementlerin \% miktarlarındaki bu artışın adsorpsiyon prosesiyle alakalı olduğu düşünülmektedir. Adsorpsiyon sonrası EDX analizinde demir elementine rastlanmamıştır.
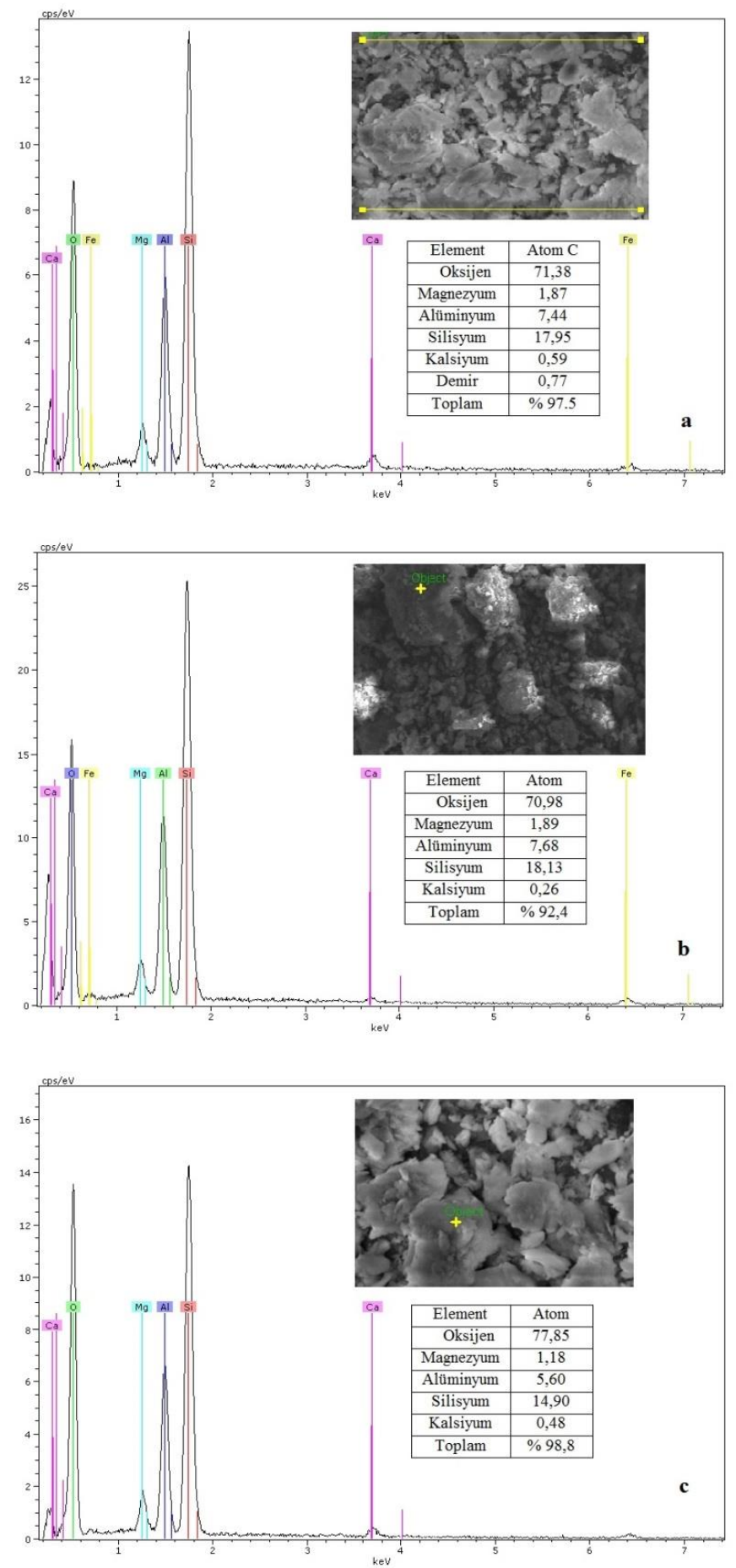

Şekil 5. MANB'in SEM-EDX verileri a) adsorpsiyon öncesi b) $P$ adsorpsiyon sonrast c) 4-CP adsorpsiyon sonrast.

\subsection{DTA-TGA Analizi}

DTA/TG, bir numunenin termal özelliklerini tek bir deneyde karakterize edebilen eşzamanlı bir termal analiz cihazıdır. TG bileşeni, ayrışma, indirgeme veya oksidasyonun meydana geldiği sıcaklıkları ölçer. Eşzamanlı olarak ayrışma, oksidasyon ve örnek kilo kaybı veya kazancı ile sonuçlanan diğer fiziksel veya kimyasal değişikliklerle ilişkili ağırlık değişikliklerini ölçer. DTA bileşeni, ayrışma işlemlerinin endotermik veya ekzotermik olup olmadığını gösterir. DTA ayrıca erime, kristalleşme ve cam geçişleri gibi kütle kaybının meydana gelmediği faz değişikliklerine karşılık gelen sıcaklıkları da ölçer 
(Kara, 1999). Modifiye edilmiş nanobentonit numunelerinin 700-1000 ${ }^{\circ} \mathrm{C}$ sıcaklık aralığında termal analizi için yapılan DTA-TG analiz grafikleri Şekil 6' da verilmiştir. Şekil 6a ve 6c' de $150^{\circ} \mathrm{C}$ de bağlı suyun uzaklaştığı bir ekzotermik pik oluşturduğu görülmüştür. Şekil $6 b^{\prime}$ de, Şekil $6 a$ ve $6 c^{\prime}$ den farklı olarak $400^{\circ} \mathrm{C}$ de de ekzotermik pik görülmüştür. Bunun sebebi, $400^{\circ} \mathrm{C}$ 'nin üzerindeki sıcaklıklarda hidroksil gruplarının ve $\mathrm{CO}_{2}$ 'in dekompozisyonu gerçekleşir (Sarıgök, 1987, Oruçoğlu vd., 2010, Yariv, 2004, Bors vd., 2001, Xie vd., 2001a, 2001b, Kozak and Domka 2004, Dultz vd., 2005, Yildız vd., 2006, Akçay, 2006, Zhu and Chen 2000, Zhu Zhu 2007, Majdan vd., 2008, Atia, 2008).
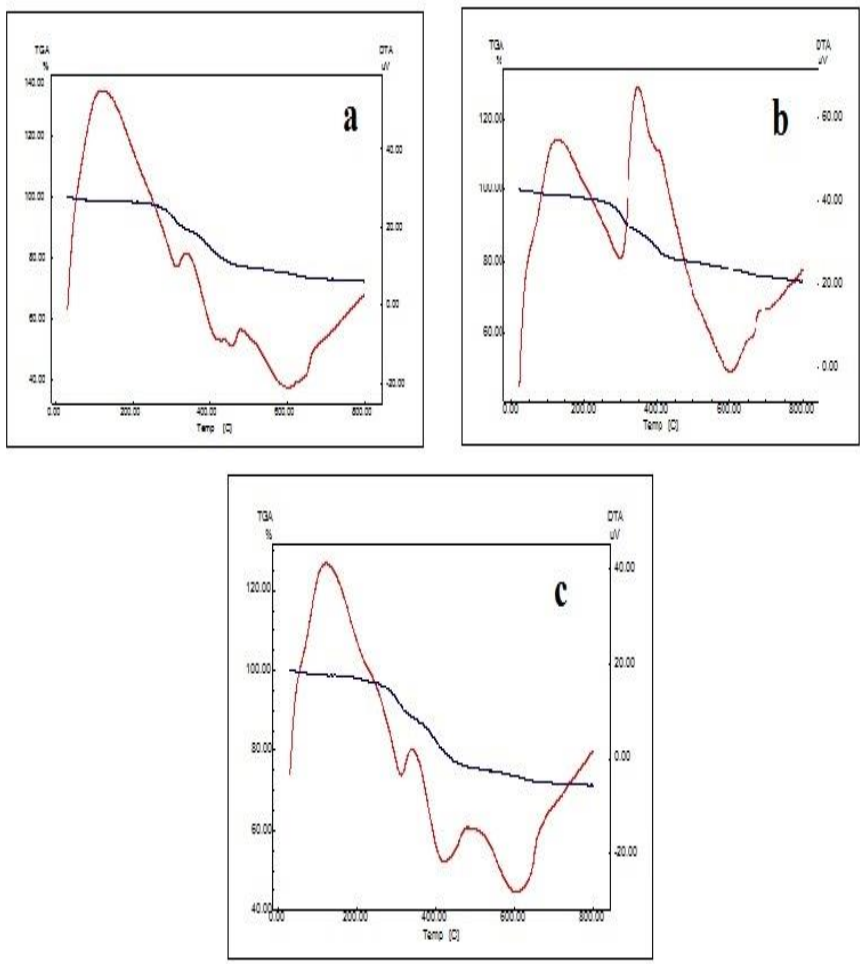

Şekil 6. MANB'in DTA-TG grafikleri a) adsorpsiyon öncesi b) $P$ adsorpsiyon sonrasi c) 4-CP adsorpsiyon sonrasi.

\subsection{FT-IR Analiz Sonuçları}

MANB'in adsorpsiyon öncesi ve sonrası FT-IR analizine ait grafikler Şekil 7-9' da verilmiştir. Şekil 7-9'da FT-IR analizlerine ait dalga boyları ve bunlara ait gerilme ve titreşim pikleri Tablo 2'de verilmiştir.

Tablo 2. Çalışmada kullanılan malzemelerin IR bantları ve karşılık gelen grupları.

\begin{tabular}{|c|c|}
\hline Dalga Sayısı $\left(\mathrm{cm}^{-1}\right)$ & Gruplar \\
\hline $3400-3700$ & $\mathrm{OH}$ gerilme piki \\
\hline $2900-2850$ & $\mathrm{CH}$ titreşimi \\
\hline $1666-1472-1467$ & $\mathrm{C}=\mathrm{C}$ zincir gerilmesi \\
\hline 1036- 1041-1040 & $(\mathrm{Al}, \mathrm{Si})-\mathrm{O}$ bağ \\
\hline 732 & $\mathrm{Si}-\mathrm{O}$ bağ 1 \\
\hline
\end{tabular}

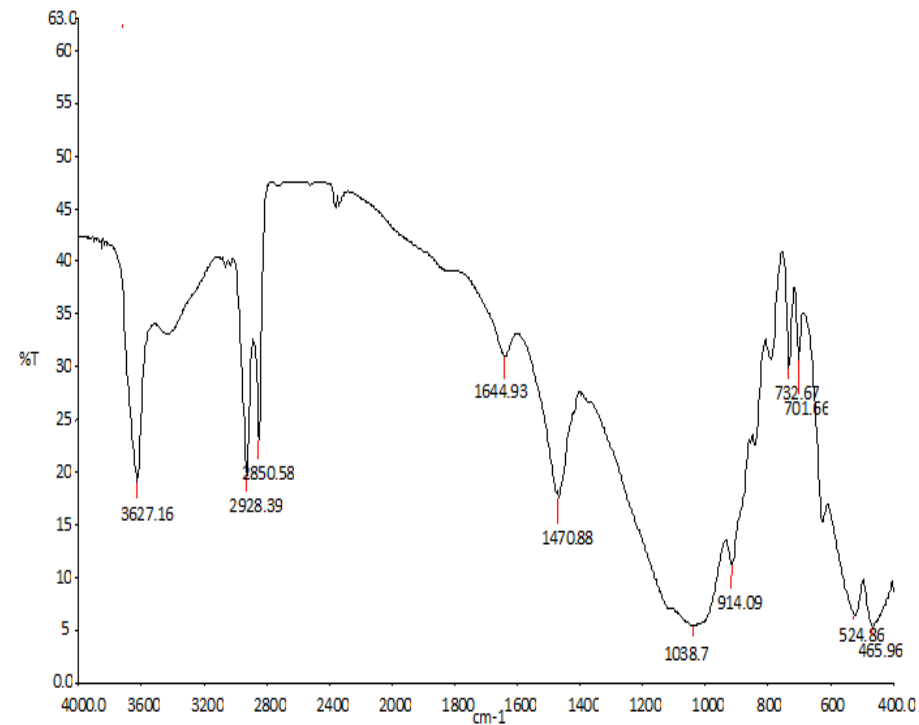

Şekil 7. MANB'in FT-IR spektrumu.

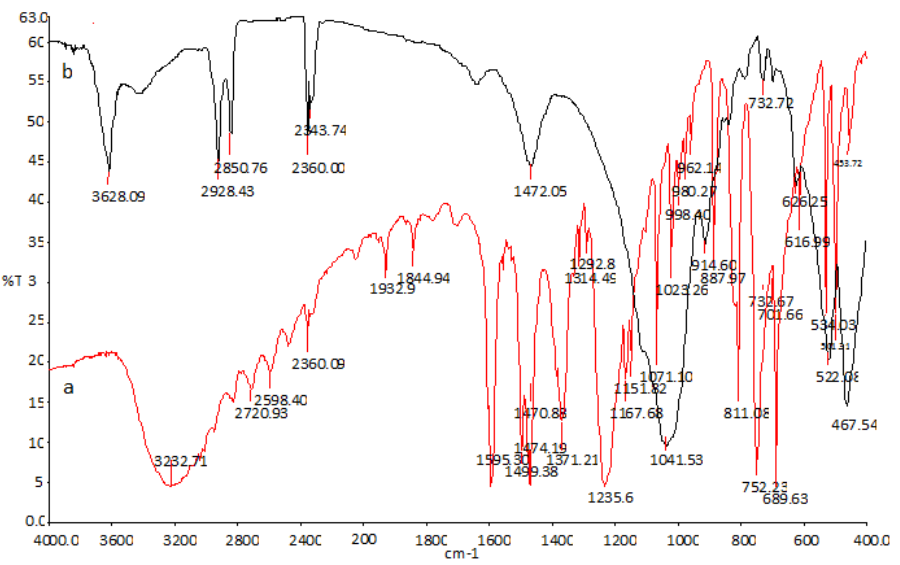

Şekil 8. MANB' 'in FT-IR spektrumu a) P adsorpsiyonu öncesi b) $P$ adsorpsiyonu sonrast.

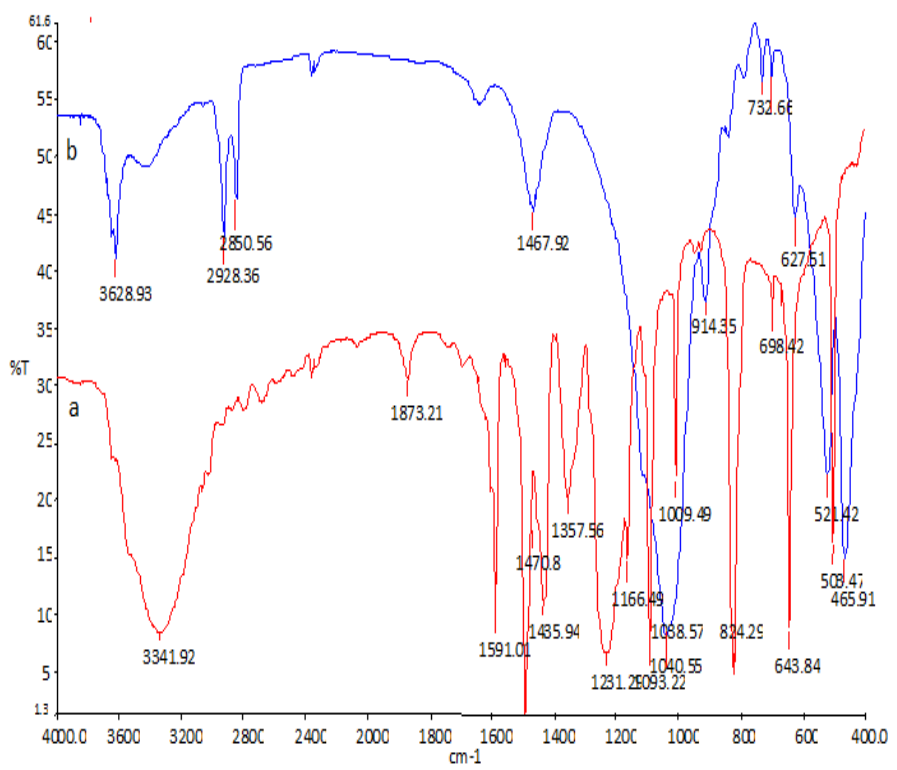

Şekil 9. MANB'in a) 4-CP b) 4-CP adsorpsiyonu sonrası FT-IR spektrumu. 
Doğal pH' da $(6,38 \pm 1) \mathrm{P}$ ve 4-CPün kalibrasyon eğrileri çizilmiş $\mathrm{P}$ için doğru denklemi $\mathrm{y}=0,0043 \mathrm{x}+1,5979$, $\mathrm{R}^{2}=0,9903$ ve 4 - klorofenol için $\mathrm{y}=0,01 \mathrm{x}+1,509 \quad \mathrm{R}^{2}=0,9938$ çıkmıştır.

\subsection{Adsorpsiyon Sonuçları}

\subsubsection{Adsorpsiyon Zamanı}

MANB'e adsorplanan P ve 4-CP'ün zamana bağlı değişimi Şekil 10' da verilmiştir.

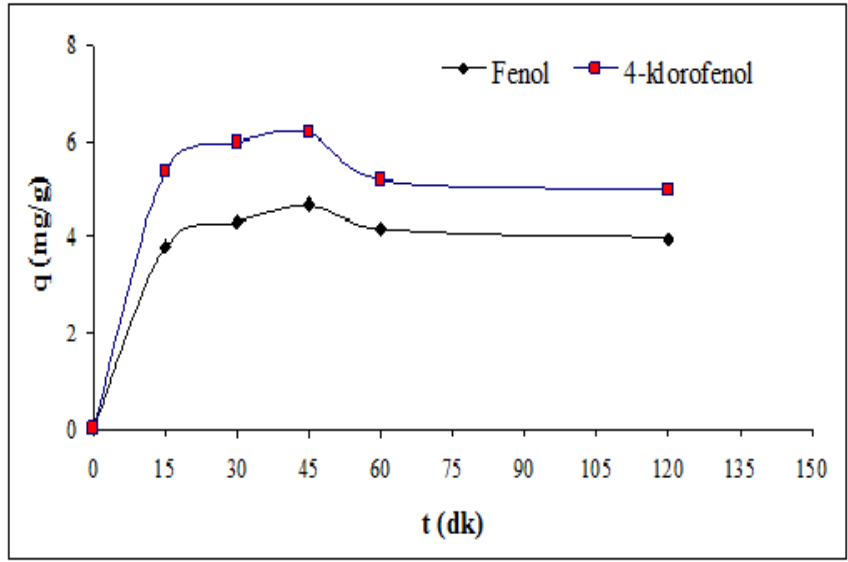

Şekil 10 Modifiye edilmiş nanobentonit $P$ ve $4-C P$ adsorpsiyonun zamana bağll değişimi $\left(C_{o}=100 \mathrm{mg} / \mathrm{L}, T=25^{\circ} \mathrm{C}\right.$, $p H=6,38 \mathrm{k} / \mathrm{s}=5 \mathrm{~g} / \mathrm{L}$, karıştırma hızl $=200 \mathrm{D} / \mathrm{D})$.

\subsection{2. pH Etkisi}

$\mathrm{P}$ ve 4-CP adsorpsiyonuna $\mathrm{pH}$ etkisi incelenmiş ve sonuçları Şekil 11'de verilmiştir.

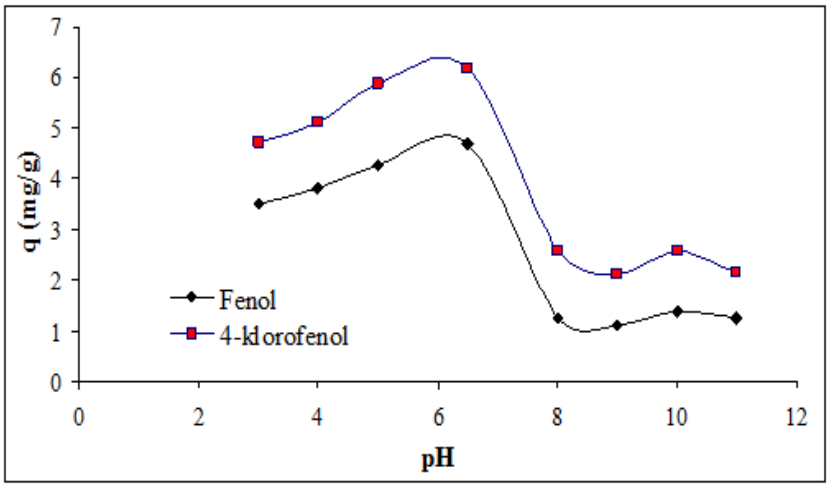

Şekil 11 MANB'e $P$ ve 4-CP adsorpsiyonunun $p H$ ile değişimi $\left(C^{o}=100 \mathrm{mg} / \mathrm{L}, \quad T=25{ }^{\circ} \mathrm{C}, \mathrm{k} / \mathrm{s}=5 \mathrm{~g} / \mathrm{L}, \quad t=45 \mathrm{dk}\right.$ karıştırma $\left.h_{\imath z l}=200 \mathrm{D} / \mathrm{D}\right)$.

\subsubsection{Adsorbent Dozaj Etkisi}

$\mathrm{P}$ ve 4-CP adsorpsiyonuna adsorbent dozaj miktarı incelenmiş ve deneysel bulguları Şekil 12'de verilmiştir.

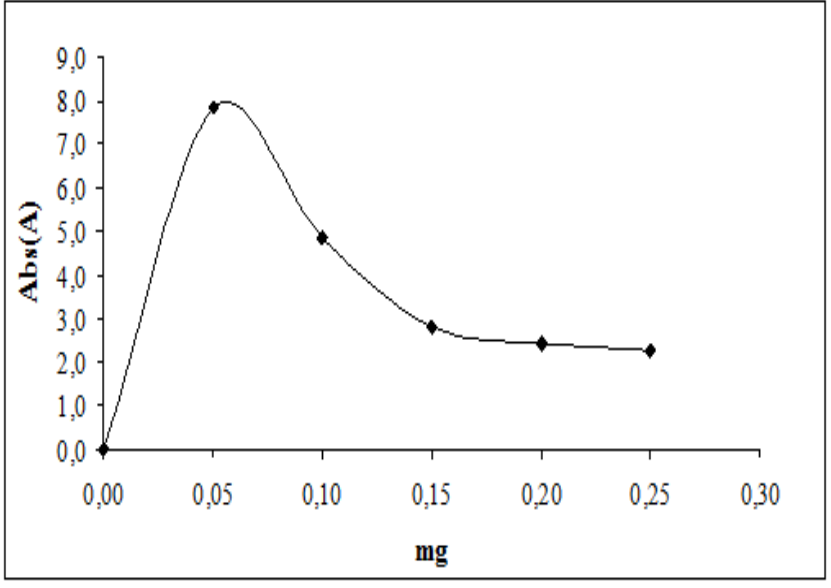

Şekil 12 Adsorban (MANB) doz miktarl $\left(C_{o}=100 \mathrm{mg} / \mathrm{L}, \mathrm{T}=\right.$ $25^{\circ} \mathrm{C}, t=45 \mathrm{dk}$ karıştırma hızı $\left.=200 \mathrm{D} / \mathrm{D}\right)$.

\subsubsection{Sıcaklı̆̆ın Etkisi}

$\mathrm{P}$ ve 4-CP adsorpsiyonuna sıcaklık etkisi incelenmiş ve termodinamik verileri Tablo 3'de verilmiştir.

Tablo 3 Modifiye Edilmiş Nanobentonitin Entalpi ve Entropi Değişimleri.

\begin{tabular}{|l|l|l|l|l|l|}
\hline & $\Delta \mathrm{H}^{0}$ & $\Delta S^{0}$ & \multicolumn{3}{|l|}{$\Delta \mathrm{G}^{0}(\mathrm{kj} / \mathrm{mol})$} \\
\cline { 4 - 6 } Adsorbat & \multirow{2}{*}{$(\mathrm{kj} / \mathrm{mol})$} & \multirow{2}{*}{$(\mathrm{kj} / \mathrm{mol})$} & $298^{\circ} \mathrm{K}$ & $318^{\circ} \mathrm{K}$ & $\mathbf{3 3 8} \mathrm{K}$ \\
\hline $\mathbf{P}$ & $-10,122$ & $-0,028$ & $-1,594$ & $-1,340$ & $-0,884$ \\
\hline 4-CP & $-19,752$ & $-0,059$ & $-2,128$ & $-1,187$ & $-0,934$ \\
\hline
\end{tabular}

\subsubsection{Konsantrasyon Etkisi}

$P$ ve 4-CP adsorpsiyonuna konsantrasyon etkisi incelenmiş ve sonuçlarl Şekil 13 ve 14'de verilmiştir.

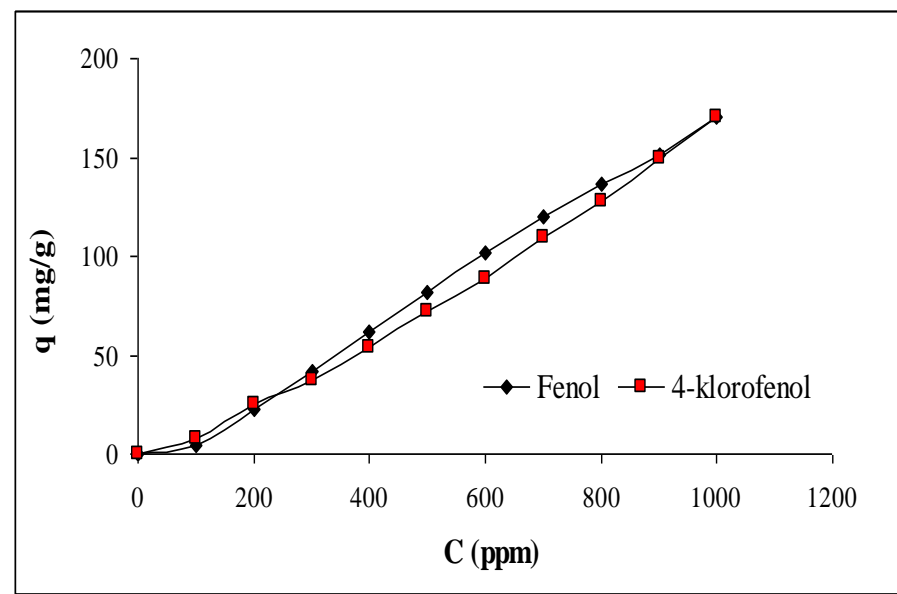

Şekil 13 MANB'e adsorplanan $P$ ve 4-CP'ün konsantrasyonla değişimi $\left(p H=6,38, T=25^{\circ} \mathrm{C}, \quad\right.$ karıştırma $h ı z l=200 \mathrm{D} / \mathrm{D}, \mathrm{k} / \mathrm{s}=5 \mathrm{~g} / \mathrm{L}, t=45 \mathrm{dk})$. 


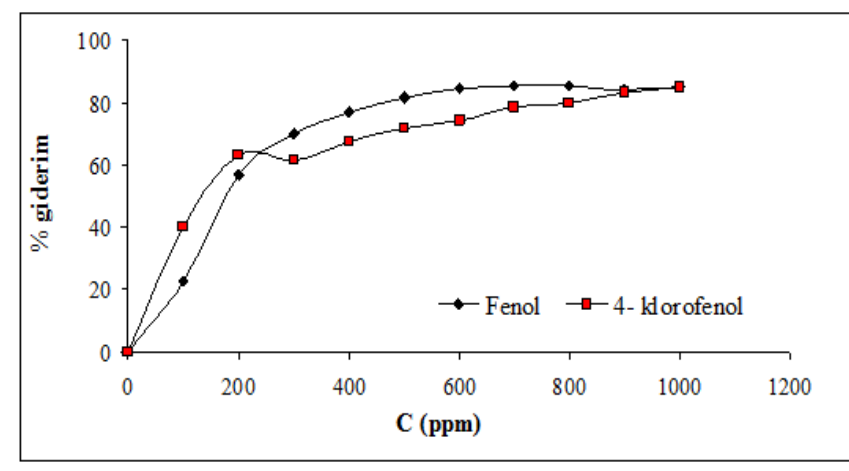

Şekil 14 MANB'e adsorplanan $P$ ve 4- CP'ün \% giderim verileri $\left(p H=6,38, T=25^{\circ} \mathrm{C}\right.$, karıştırma hızı $=200 \mathrm{D} / \mathrm{D}, \mathrm{k} / \mathrm{s}=5$ $g / L, t=45 d k)$.

\subsubsection{Adsorpsiyon İzotermleri}

$\mathrm{P}$ ve 4-CP adsorpsiyonun kinetik parametreleri Tablo 4'de verilmiştir.

Tablo 4 MANB'in Freundlich ve Langmuir İzoterm verileri $\left(T=25^{\circ} \mathrm{C}, \mathrm{pH}=6,8\right.$ karlştırma hızı $\left.=200 \mathrm{D} / \mathrm{D}, \mathrm{k} / \mathrm{s}=5 \mathrm{~g} / \mathrm{L}\right)$.

\begin{tabular}{|l|l|l|c|l|l|l|}
\hline Adsorban & $\begin{array}{l}\text { Freundlich } \\
\text { Katsaylan }\end{array}$ & $P$ & 4-CP & $\begin{array}{l}\text { Langmuir } \\
\text { Katsaylann }\end{array}$ & P & 4-CP \\
\hline \multirow{2}{*}{ Nanobentonit } & $\mathrm{K}_{\mathrm{P}}$ & 0,0049 & 0,8650 & $\mathrm{~K}_{\mathrm{L}}$ & $-0,0030$ & 0,0600 \\
\hline & $1 / n$ & 1,6723 & 1,2020 & $\mathrm{Q}^{0}$ & $-177,5710$ & $-20,0000$ \\
\cline { 2 - 7 } & $\mathrm{R}^{2}$ & 0,9706 & 0,9416 & $\mathrm{R}^{2}$ & 0,6645 & 0,9467 \\
\hline
\end{tabular}

\subsubsection{Katyon Değiş̧im Kapasitesi}

KDK verileri Tablo 5'de verilmiştir.

Tablo 5 MANB'e ait KDK değgerleri.

\begin{tabular}{|l|l|l|l|}
\hline KDK & MNPB & $\mathbf{P}$ & 4-CP \\
\cline { 2 - 4 }$(\mathbf{m e q} / \mathbf{1 0 0 g})$ & 27,17 & 16,30 & 10,87 \\
\hline
\end{tabular}

\section{Sonuç}

MANB için adsorpsiyon denge süresi, $100 \mathrm{mg} / \mathrm{L}$ başlangiç derişiminde $\mathrm{P}$ ve 4-CP için belirlenmiştir. $\mathrm{Bu}$ maddelerin adsorpsiyonunun başlangıçta son derece hızlı olduğu ve yaklaşık 45 dakika içinde doygunluk yüzey konsantrasyonuna ulaştığ gözlenmiştir.

$\mathrm{P}$ ve 4-CP' ̈̈ adsorplayan MANB (katı/sıvı $=5 \mathrm{~g} / \mathrm{L}, \mathrm{T}=25^{\circ} \mathrm{C}$ ) ortam pH'1 doğal $\mathrm{pH}(\mathrm{pH}=6,38 \pm 1)$ olarak bulunmuştur. $\mathrm{P}$ ve 4CP'ün başlangıç derişimi $100 \mathrm{mg} / \mathrm{L}$ olduğunda $\mathrm{P}$ için $4,69 \mathrm{mg} / \mathrm{g}$, 4-CP için $6,18 \mathrm{mg} / \mathrm{g}$ adsorpladığı bulunmuştur. Adsorplama sırası 4-CP > P sırasına göre azalmaktadır.
Farklı pH' larda yapılan adsorpsiyon deneylerinde maksimum adsorpsiyonun doğal $\mathrm{pH}$ değerinin yaklaşık $\mathrm{pH}=6,38 \pm 1$ olduğu belirlenmiştir. Daha yüksek pH'larda adsorpsiyon miktarının azaldığı gözlenmiştir.

MANB $\mathrm{P}$ ve 4-CP'ün adsorpsiyonu fenollerle bentonit yüzeyi arasındaki elektrostatik kuvvetten kaynaklanan çekim ile olduğu düşünülmektedir. Burada, zit elektrik yüklerine sahip olan adsorbant ile adsorban yüzeyinin birbirlerini çekmesi önem kazanmaktadır.

MANB'in yeniden kullanılabilirliğini belirlemek için, adsorpsiyon denemesinde kullanılan bentonit \%30 (v/v) etanol çözeltisi ile işleme tabi tutulmuş ve en az $3 \mathrm{kez}$ kullanılabileceği bulunmuştur. MANB numunlerinin DTA verileri incelendiğinde MANB'in $150^{\circ} \mathrm{C}$ de yapısındaki zayıf ve kuvvetle bağlanmış suyun uzaklaşarak bir ekzotermik pik oluşturduğu bulunmuştur.

Elde edilen verilere göre en uygun adsorpsiyon izoterm modelinin Freundlich adsorpsiyon izoterm modeline uyduğu bulunmuştur.

$25^{\circ} \mathrm{C}, 35^{\circ} \mathrm{C}$ ve $45^{\circ} \mathrm{C}$ süspansiyon sicaklıklarında yapılan deneylerinde ise sicaklığın yükselmesiyle adsorpsiyon değerlerinde azalma görülmüştür. Adsorpsiyon gideriminin \% 98-\%99 değerine kadar yükselmesi, uygulanan adsorpsiyon modeli sonucunda adsorpsiyon 1sısının $10 \mathrm{kcal} / \mathrm{mol}$ ' den düşük olması, $\quad \mathrm{P}$ ve 4-CP'ün fiziksel olarak adsorplandığını göstermektedir. Ayrıca adsorplanan ile adsorplayan arasında bağ Vander Waals çekiminden kaynaklanmaktadır.

MANB Gibbs Serbest enerji değişimi verilerinin negatif olduğu görülmektedir. Gibbs Serbest enerji değişiminde negatif değerler adsorpsiyonun kendiliğinden olduğunu kanıtlamaktadır. Değişik sıcaklıklarda yapılan adsorpsiyon deneylerinde $\Delta \mathrm{H}$ değerlerinin ( $\mathrm{P}$ için -10,122 kJ/mol, 4-CP için $-19,752 \mathrm{~kJ} / \mathrm{mol}$ ) ve $\Delta \mathrm{S}^{\circ}$ değerlerinin ( $\mathrm{P}$ için $-0,0028,4-\mathrm{CP}$ için $-0,059 \mathrm{~kJ} / \mathrm{mol}$ ) negatif olduğu bulunmuştur. $\Delta \mathrm{H}^{\prime}$ 'n negatif çıkması reaksiyonun ekzotermik olduğunu $\Delta \mathrm{S}^{\circ}$ sonuçlarının negatif çıkması ise prosesin düzensizliğinde azalma olduğunu göstermektedir. Hem $\Delta \mathrm{H}^{\prime}$ in hem de $\Delta \mathrm{S}^{\circ}$ 'negatif olması reaksiyonun düşük sıcaklıklarda kendiliğinden olduğunu göstermektedir.

Genel olarak bu çalışma değerlendirildiğinde, $P$ ve 4-CP'ün MANB kullanılarak uzaklaştırılmasında etkili doğal bir adsorbent olabileceği sonucuna varılmış ve çok düşük maliyetli ve kolay bir metodla uzaklaştırılabileceği bulunmuştur.

\section{Teşekkür}

Yazarlar, eleştirel yorumları ve makalelerinin kalitesini önemli ölçüde artıran faydalı önerileri için hakemlere ve adsorbanı temin eden sayın Prof. Dr. Marek Majdan'a teşekkür eder.

\section{Kaynakça}

Ahmaruzzaman M. (2008). Adsorption of phenolic compounds on lowcost adsorbents: A review. Advances in Colloid and Interface Science, 143, 48-67.

Akçay M. (2006). Characterization and adsorption properties of tetrabutyl ammonium montmorillonite (TBAM) clay: 
Thermodynamic and kinetic calculations. Journal of Colloid and Interface Science, 296, 16-21.

Aksu, Z. ve Yener, J. (2001). Comparative adsoption/biosorption study of monochlorinated phenols onto various sorbents. Waste Management, 21, 695-702.

Atia, A.A. (2008). Adsorption of chromate and molybdate by cetylpyridinium bentonite. Applied Clay Science, 41, 73-84.

Banat, F. A., Al-Bashir, B., Al-Asheh, S., Hayajneh, O. (2000). Adsorption of phenol by bentonite. Environmental Pollution, 107, 391-398.

Bors, J., Patzko, A., Dekany, I. (2001). Adsorption behavior of radioiodides in hexadecylpyridiniumhumate complexes. Applied Clay Science, 19, 27-37.

Dabrowski, A., Podkoscielny, P., Hubicki, Z., Barczak, M. (2005). Adsorption of phenolic compounds by actived carbon-a critical review. Chemosphere,58, 1049-1070.

Dann, S.E. (2002) Reactions and Characterization of Solids (Basic Concepts In Chemistry), Royal Society of Chemistry, Chambridge, 201.

Denizli, A., Özkan G. and Uçar M., (2002), Dye-affinity microbeads for removal of phenol and nitrophenols from aquatic systems. Journal of Applied Polymer Science, 83 (11), 2411-2418

Denizli, A., Özkan G and Uçar M, (2001). Removal of Chlorophenols from Aquatic Systems with Dye-affinity Microbeads. Separation and Purification Technology, 24, 255-262.

Dultz, S., Riebe, B., Bunnenberg, C. (2005). Temperature effects on iodine adsorption on organo-clay minerals II. Structural effects. Applied Clay Science, 28,17-30.

Evcin A., Uçar M., Kayıran D., Selimoğlu M., 4 Klorofenolün Hidroksiapatit ile Sulu Ortamdan Uzaklaştırılması. AKÜ FEMÜBİ 14 (2014) OZ5737 (233-237).

Garmia D., Zaghouane-Boudiaf H., Viseras Ibbora C., (2018). Preparation and characterization of new low cost adsorbent beads based on activated bentonite encapsulated with calcium alginate for removal of 2,4-dichlorophenol from aqueous medium. International Journal of Biological Macromolecules, 115, 257-265.

Hernández-Hernández, K.A., Illescas, J., Díaz-Nava, C., MartínezGallegos, S., Muro, C. ,Ortega-Aguilar, R., Rodríguez-Alba, E., Rivera, E., (2018). Preparation of nanocomposites for the removal of phenolic compounds from aqueous solutions. Applied Clay Science. 157, 212-217.

İpekoğlu, B., Kurşun, İ., Bilge, Y., Barut, A. (1997). Türkiye Bentonit Potansiyeline Genel Bir Bakış. 2. Endüstriyel Hammaddeler Sempozyumu, 16-17 Ekim İzmir, 51-57.

Kara, M. (1999). Toksik Ağır Metal İyonlarının Sepiyolit Üzerine Adsorpsiyon Mekanizması (Doktora Tezi), İTÜ, İstanbul, s.247.

Kozak, M., and Domka, L. (2004). Adsorption of the quaternary ammonium salts on montmorillonite. Journal of Physics and Chemistry of Solids, 65:441-445.

Kuleyin A. (2007). Removal of Phenol and 4-Chlorophenol by Surfactant- Modified Natural Zeolite. Journal of Hazardous Materials, 144, 307-315.

Kuśmierek, K. (2016). The removal of chlorophenols from aqueous solutions using activated carbon adsorption integrated with $\mathrm{H}_{2} \mathrm{O}_{2}$ oxidation. Reaction Kinetics, Mechanisms and Catalysis, 119, 1934.

Majdan, M., Maryuk, O., Gladysz-Plaska, A., Pikus, S., Kwiatkowski, R., (2008). Spektral characteristics of the bentonite loaded with benzyldimethyloctadecyl ammonium chloride, hexadecyltrimethyl ammonium bromide and dimethyldioctadecyl ammonium bromide. Journal of Molecular Structure, 874, 101-107.

Nourmoradi H., Avazpour M, Ghasemian N, Heidari M, Moradnejadi K., KhodarahmiF., Javaheri M., Mohammadi Moghadam F., (2016). Surfactant modified montmorillonite as a low cost adsorbent for 4- chlorophenol: Equilibrium, kinetic and thermodynamic study. Journal of the Taiwan Institute of Chemical Engineers, 59, 244-251. Olaniran A.O., Igbinosa, E.O,. (2011). Chlorophenols and other related derivatives of environmental concern: properties, distribution and microbial degradation processes. Chemosphere 83, 1297-1306.

Pera-Titus, M., Garcia-Molina V., Baños MA., Gimenez J., Esplugas, S, (2004). Degradation of chlorophenols by means of advanced oxidation processes: a general review. Appl Catal B Environ 47, 219-256.

Oruçoğlu, E ve Haciyakupoğlu, S, (2010). Organo-bentonitler ve karakterizasyonlarında kullanilan yöntemler. İstanbul Teknik Üniversitesi, Maden Fakültesi, Enerji Enstitüsü, Ayazağa Kampüsü, İstanbul.

Sarıök, Ü, (1987). Anorganik Endüstriyel Kimya, Güryay Matbaacılık, İstanbul.

Sanjay P, K., Priti A, M., Amit K, B and Sadhana S, R (2008). Adsorption of phenol and o- chlorophenol on surface altered fly ash based moleculer sieves. Chemical Engineering Journal, 138, 73-83.

Soto ML, Moure A, Dominguez H and Parajo J.C., (2011). Recovery, concentration and purification of phenolic compounds by adsorption: a review. J Food Eng,105,1-27.

Şenel S, Kara A, Alsancak G and Denizli A, J. Hazardous Materials, (2006). B138, 317-324.

Şentürk, H.B., Özdeş D., Gündoğdu A., Duran C., Soylak M., (2009). Removal of Phenol from Aqueous Solutions by Adsorption Onto Organomodified Tirebolu Bentonite: Equilibrium, Kinetic and Thermodynamic Study. Journal of Hazardous Materials, 172, 353362.

Uçar S. (2009). Sulu Ortamda Bulunan Fenol ve Klorofenollerin Aktive Edilmiş Klinoptilolit Kullanılarak Uzaklaştırılması (Yüksek Lisans Tezi). Afyon Kocatepe Üniversitesi, Fen Bilimleri Enstitüsü, Afyonkarahisar.

Uçar, M., Evcin, A., Kayıran, D., Ünverdi, H., Klorofenolün $\mathrm{Al}_{2} \mathrm{O}_{3}$ Katkılı Hidroksiapatit ile Sulu Ortamdan Uzaklaştırılması. $A K \ddot{U}$ FEMÜBID 14 (2014). OZ5737, (225-232).

Uçar, S., Evcin, A., Uçar, M., Alibeyli, R., Majdan, M (2015). Aktive Edilmis Klinoptilolit Kullanılarak Sulu Ortamdan Fenol ve Klorofenollerin Uzaklastır1mas1. Hacettepe Journal of Biology and Chemistry, 43(3), 235-249.

Uçar M., (2019). Adsorption of chlorophenolic compounds on activated clinoptilolite, Adsorption Science \& Technology, 37, 664-679.

Uçar, M., Erçolak, K ve Uçar S., (2020). Removal of Phenol and Nitrophenols from Aquatic System With Cibacron Blue F3GA Attached mPHEMA, El-CezerîJournal of Science and Engineering, 7 (3), 1518-1528.

Xie, W., Gao, Z., Liu, K., Pan, W.P., Vaia, R., Hunter, D and Singh, A. (2001a) Thermal characterization of organically modified montmorillonite. Thermochimica Acta, 367-368, 339-350.

Xie, W., Gao, Z., Pan, W.P., Hunter, D., Singh, A., Vaia, R. (2001b) Thermal degradation chemistry of alkyl quaternary ammonium montmorillonite. Chemistry of Materials, 13, 2979-2990.

Yariv, S. (2004). The role of charcoal on DTA curves of organo-clay complexes: an overview. Applied Clay Science, 24, 225-236.

Yıldız, N., Gönülşen, R ve Çalımlı, A. (2006). Tek ve çift katyonlu organobentonitlerin hazırlanması ve karakterizasyonu, Kibited, 1, 2, 93-105.

Zhu, L. and Chen, B., (2000). Sorption Behavior of p-nitrophenol on the Interface between Anion-Cation Organobentonite and Water. Environmental Science \& Technology, 32, 3374-3378.

Zhu, L., Zhu, R. (2007). Simultaneous sorption of organic compounds and phosphate to inorganic-organic bentonites from water. Separation and Purification Technology, 54: 71-76. 